\title{
The impact of fisher's risk perception on fishery outcomes in an end-to- end ecosystem model
}

\author{
Ingrid van Putten $^{\mathbf{1}^{*}}$, Bec Gorton ${ }^{\mathbf{1}}$, Beth Fulton ${ }^{\mathbf{1}}$, and Olivier Thebaud ${ }^{\mathbf{1}}$ \\ ${ }^{1}$ CSIRO Wealth from Oceans National Research Flagship, CSIRO Marine and Atmospheric \\ Research, GPO Box 1538, Hobart, Tasmania, 7001 \\ Email: Ingrid.vanputen@csiro.au
}

\begin{abstract}
Over the past three decades increasingly complex fisheries models that link biological and physical information to resource user decisions have been developed to anticipate the effects of changing government policies. The predictive accuracy of so called end-to-end models appears to depend on a solid understanding of the underlying processes and feedback systems, within and between the biological, physical and human domains.
\end{abstract}

Many fisher decisions are modelled in the human component of these fisheries models including risk. Empirical evidence suggests that fisher decision making under risk does not follow rational choice behaviour theory. Instead, fisher risk profiles have been incorporated into fisheries models to account for this. However, the contribution of risk profiles and risk related exploratory fisher behaviour on fisheries management outcomes in end-to-end models has not been explored in detail.

In this current study we unpack an end-to-end ecosystem system model and assess appropriateness and effect of using fisher responsiveness to information as the basis of fisher risk profiles. For the Southern and Eastern Scalefish and Shark fishery and its five largest fleets, we investigate if, in accordance with theoretical assumptions and empirical evidence, risk seeking (averse) behaviour pays off in terms of higher (lower) catches while incurring higher (lower) variability.

Our analysis shows that the interpretation is not straightforward and the relationship between payoff and risk profile has to be considered in the context of three main fleet characteristics: whether the fleet is profitable; how diversified the fleet is; and whether the target species biomass is growing or in decline. Moreover, if the object of the fisher's choice is to minimise income variability there is no significant difference between risk averse and risk seeking fishers.

Keywords: risk perception, fisher decision making, ecosystem model 


\section{INTRODUCTION}

It is well accepted by most fisheries scientists and managers that effective and efficient management policies depend on a good understanding of not only marine biology but also knowledge of fisher behaviour and decision making (e.g. Hilborn 1985). Understanding feedback processes between all systems is now even more pertinent considering the effect of climate change on the marine environment and the necessity to focus increasingly on adaptive management rather than prescriptive approaches (Symes and Hoefnagel 2010). Over the past three decades fisheries models have been developed for many regions in the world to help policy makers in their endeavours to sustainably manage fisheries (e.g. Fulton 2010). The form and application of fisheries models has evolved from largely single species to an increasing number of whole-of-system (or endto-end) ecosystem models (e.g. Fulton 2010). A key part of this expansion has been the inclusion of broader set of potential processes considered; both with regard to the biological and physical components of marine systems, but also to the human elements that describes resource user behaviour and their interaction with the marine environment. The models of the human components have largely relied on techniques drawn from economics (van Putten et al 2011). However, this does not include the many non-economic drivers (such as personality type, attitude, morals and norms, and risk perception; e.g. Strand 2004).

As a first step in including non-economic drivers, in our study we considered the ways in which risk perception, which is an important driver of decision making that is firmly based in the social sciences, can be incorporated in the Atlantis ecosystems model (Fulton et al 2007). We use the application of this modelling platform to the Southern and Eastern Scalefish and Shark Fishery (SESSF) as a case study, and examine the way in which individual decisions are modelled at fleet level, and how they combine to produce the fleet behaviour observed in the model, in response to management changes. We test whether these reflect particular assumptions about fisher risk perceptions and risk profiles as presented in the literature, and whether using 'habit' as a proxy is a useful approach in ecosystem models. We focus mainly on fisher location choice behaviour and fishing effort expended as moderated by the risk of income variability and health and safety risk.

\section{RISK, RISK PERCEPTION, AND RISK TYPOLOGIES}

Rational choice theory has been the main way in which human decision making is described in integrated fisheries models. This theory assumes an individual has a set of possible actions with potential consequences for each action; rational choice then defines that the agents order the actions according to preferences over the expected consequences and chose the highest ranking option. Given that the consequences of each action may depend on the uncertain state of the world that eventuates, the problem of choosing between actions can be cast in terms of a choice between lotteries. When consequences of this decision are measured in monetary terms, the agent's attitudes towards risks of losses and gains to be characterized. A constant relation between utility and gains implies risk neutrality, or indifference towards risk, while a concave relation will indicate risk aversion (the utility of a certain outcome being higher than the utility of a lottery with the same expected outcome). There have been many extensions to this standard model of decision-making under risk, largely grounded in micro-economic theory (e.g. Kahneman \& Tversky 1979; Sjøberg 2001).

In the context of fisheries, the concept of risk has been used to characterize a wide range of decision problems facing fishers including profit (e.g. Christensen and Raakjær 2006) health and safety (e.g. Schnier et al 2009), weather (e.g. Smith \& Wilen 2005), compliance (e.g. Nøstbakken 2008), investment (e.g. Hilborn and Ledbetter 1979), and policy and management (e.g. Dwyer and Minnegal 2006). Econometric methods that derive fisher risk typologies are largely based on observed fishing behavioural data; where the sign of the coefficient on variability (in terms of revenue, profit or wealth) is used as an indicator of the average risk preference (e.g. Holland and Sutinen 1999). Risk averse fishers are less likely to fish in areas where the variability in catch, and thus profit, is high (Pradhan and Leung 2004). Meaning they visit the fishing locations where they have been successful in the past (Pascoe and Mardle 2005; Strand 2004). The location choice literature that employs such an econometric approach suggests that fishers are largely risk averse.

Previous simulation study by Allen and McGlade (1987) has included risk profiles (or attitudes) for fisher location choice behaviour; with empirically determined risk profiles incorporated into a fisheries model for the Nova Scotia Groundfish Fishery to assess the management implications for the fishery and to evaluate the role of information as used by so-called "stochast" and "cartesian" fishers on location choice behaviour in a single species model. In this model the 'attractiveness' of a location is dependent on expected profit, the information exchange between fishers and fleet, and the response of the skipper to the information received. The skipper's response to the information is a function of their risk profile. Stochasts may disregard 
information received making their location choice random and thus discovering new areas that lead to switching in the investment of fishing effort. Cartesian fishers believe all the information they receive and respond accordingly ensuring that progress and adaptation occurs smoothly and not only by catastrophic collapse and replacement.

In this current research we build on, and extend, Allen and McGlade's (1987) single species model by investigating the effect of behavioural assumptions regarding changes in fishing effort and its spatial distribution in the Atlantis ecosystem model, using the Southern and Eastern Scalefish and Shark Fishery (SESSF) as a case study. We evaluate different scenarios and compare them in terms of the implied attitudes towards risk of the fishing fleets modeled. We use these results to discuss the implications for the fishery and its management.

\section{MODEL DESCRIPTION AND METHODOLOGY}

The Atlantis modelling framework is an end-to-end model presently used to support marine ecosystem-based management (Fulton et al 2004). Atlantis' biophysical component is a deterministic (differential equation), spatially resolved, three-dimensional spatial model. Although in our analysis we include biological impacts for the SESSF, we mainly focus on the human impacts predicted by the model (for more biological model details see Fulton et al 2005).

The human impacts sub-model in Atlantis deals with the dynamics of multiple and specifically detailed fishing fleets (Fulton et al 2007). A hierarchical effort allocation model and planning scheme is used for determining the scale and distribution of fishing effort. In a quasi-agent-based approach, boats of similar size with common home ports, socio-economic backgrounds or other aggregate behavioural features are referred to as subfleets. These subfleets explicitly step through effort allocation decisions based on current economic conditions, distance to fishing grounds, management regulations, and importantly, a memory of past conditions. Fisher's effort scheduling according to previous fishing behaviour is sometime referred to as 'the black book' approach (Fulton et al. 2007). The final step in the annual effort scheduling is to spatially allocate the expected gross monthly effort and in this final step a measure of fisher flexibility is taken into account.

Fishers in Atlantis build up knowledge of the fishery system through personal experience, which is captured in the annual effort scheduling. After all, not all fishers use historically gained information in the same way, and thus not all fishers behave in the same way. Similar to Allen and McGlade (1987), fishers in Atlantis who place a low weight on a new schedule and therefore do not place a high weight on updating their previous fishing experience, are labeled traditionalists, others are labeled flexible fishers (Equation 1). The heuristically tuned flexibility parameter dictates the fisher's willingness to weight the most recent catch and effort data over longer term patterns. Due to lack of empirical data for the SESSF, Fulton et al (2007) parameterised the flexibility term by retrofitting the effort allocation model to reproduce the shifts in allocation and targeting as observed during the 1990s. The fishers' annual effort scheduling is further confounded with the ability to move on, which may be constrained by onshore social and economic issues or technical availability. For all types, the effort updating is calculated using:

$$
E_{i, j, m, \text { current }, b}=\text { weight }_{i, j}\left(E_{e, i, j, m, b}-E_{h, i, j, m, b}\right)+E_{h, i, j, m, b}
$$

where $E_{e, i, j, m, b}$ is effort per box $(b)$ and month $(m)$ for subfleet $i$ of fishery $j$ based on expectations created using recent experience and conditions; $E_{h, i, j, m, b}$ is effort per cell and month for subfleet $i$ of fishery $j$ based on historical patterns and memory; and the coefficient for flexibility is given by weight $t_{i, j}$ with a low weight indicating those who rely more heavily on historical information. Although past behaviour of this group impacts later behaviour we acknowledge that in reality it is not a causal factor in itself (Ajzen, 1987) and, even though we later refer to this type of behaviour as 'habitual', we acknowledge that it is not independent of beliefs, subjective norms and intentions (Ajzen, 1991). In essence we assume that past experience together with a reasoned response lead to habitual behaviour. In contrast, those with a high weight have the capacity to be more responsive to new information and conditions and display more flexible behaviour.

The final schedule in Atlantis is spatially allocated in proportion to the effort applied by the subfleet to each spatial box in each month, so that the planned effort in a box $b$ in month $m$ by the subfleet (Eplan,i,j,b, $m)$ is: 


$$
E_{p l a n, i, j, b, m, y}=E_{e, i, j, m, y} \frac{E_{h, i, j, b, m}}{E_{h, i, j, m}}
$$

with $E e, i, j, m, y$ the scheduled monthly resolved effort for the subfleet, Eh,i,j,m the historical levels of effort for the month and $E h, i, j, b, m$ the level of effort by the subfleet historically seen in box $b$ in month $m$. We assess the effect of different assumptions about fisher responsiveness in the SESSF primarily by varying the flexibility coefficient and evaluating the impact of this on planned and realized effort, for the dynamic component of the fleet, as well as on the economic consequences for the fleet. Our hypothesis is that the model can be used to examine the extent to which the behavioural assumptions regarding fishing effort allocation are related to a type of attitude towards risk.

We used the Atlantis model to run a basecase and 2 risk profile scenarios with different flexibility coefficients $(\delta)$ values. For our basecase the flexibility term was parameterised by retrofitting the effort allocation model to reproduce the shifts in allocation and targeting as observed during the 1990s (Fulton et al 2007). For the basecase the coefficient is set individually for each sub-fleet within a fleet. For instance, the demersal trawl fleet has five subfleets. These fleets target deep piscivorous and demersal fish, such as ling (Genypterus blacodes), blue grenadier (Macruronus novaezelandiae) and gemfish (Rexea solandri), as well by-catch species (including deep water sharks and dogfish, and miscellaneous deep water invertebrates). The flexibility coefficient for the 26 smallest vessels was set at 0.1 . The flexibility coefficient increased to 0.15 for the 6 medium size vessels, and to 0.2 and 0.225 for slightly larger and largest vessel respectively. Larger vessels are assumed to be better equipped for exploratory fishing.

The first scenario, which we labelled this the risk averse (traditional) fisher scenario, characterises the fishery by a low flexibility coefficient of 0.05 as the fleet relies on historical information to make decisions (based on Allen and McGlade 1987). In the second scenario the flexibility coefficient was set at a high value (0.95). We labelled this the risk seeking (flexible) fisher scenario as the fleet is more responsive to new information and conditions. We model expected and realised effort, expected and realised catch, and expected and realised CPUE and present differences in outcomes for the basecase and the two scenarios for the whole SESSF. We also detail the outcomes for five dynamic fleets in the SESSF fishery

\section{RESULTS}

Each fleet annually adjusts their expected catch for each species up, down, or retains it at the same level, on the basis of catches in the previous year(s). The difference between expected and realized catch for each of the scenarios is shown in Figure 1.

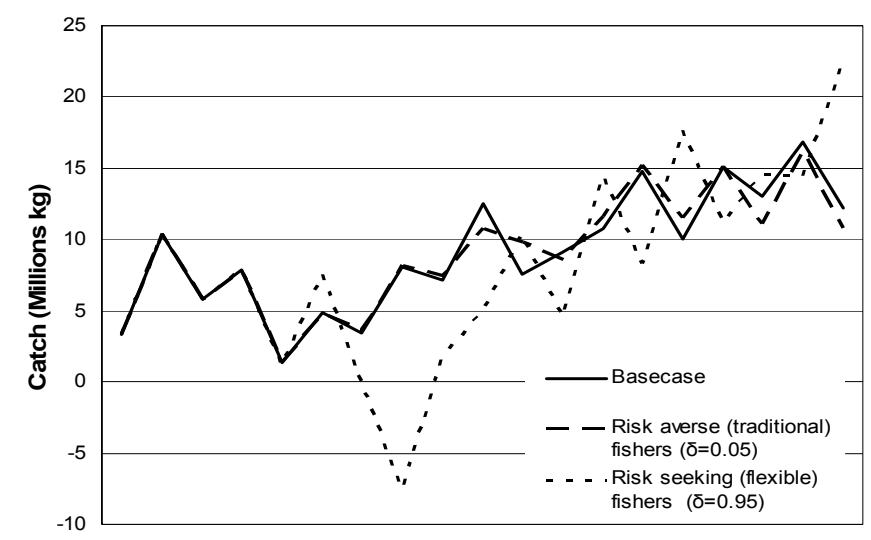

Figure 1: The difference between annual expected and realised catch for the base case and two flexibility scenarios for the SESSF fishery.

Realised catches are greater than expected catches for the 20 year period for the basecase and risk averse (traditional) fisher scenario, that is where values are greater than zero in Figure 1. On average over the entire period realised catches are $25 \%$ higher than expected catches. In the risk seeking (flexible) fisher scenario 
van Putten et. al. The impact of fisher's risk perception on fishery outcomes....

catch is overestimated and expectations outstrip realised catches between years 6 and 9, indicating that risk seeking fishers are 'over optimistic' in those years.

When considering the whole SESSF, cumulative realised catches over the 20 year period are 6 percent (around 52,414 tonnes) lower for risk seeking fishers than for the basecase and risk averse fishers. For risk seeking fishers both realised catches and realised effort are lower rendering a higher CPUE. In a fishery that is only marginally profitable, greater flexibility in reducing effort pays off. In terms of realised CPUE risk seeking fishers in the SESSF are around 30\% more efficient. Aside from greater efficiency (based on realised CPUE), the cumulative gross value over the 20 year period is also $1 \%$ higher for risk seeking fishers.

Targeting behaviour changes over the 20 year period changes as the biomass of some species decreases or increases and as opportunities arise (Figure 2).

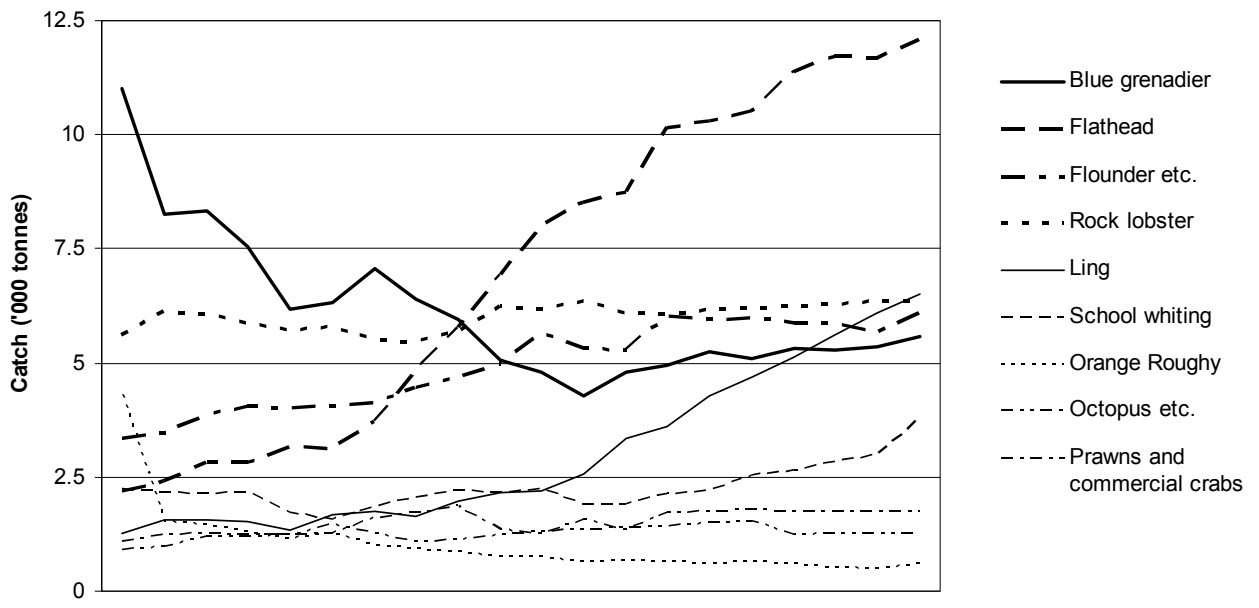

Figure 2: Catch of the main species for the SEFFS fishery (20 years - basecase).

The largest relative fall in biomass in the basecase are observed for Blue Grenadier and orange roughy. The biomass of Flathead and Ling increases over the 20 year period. Risk seeking fishers switch targets temporarily moving from targeting mainly piscivorous fish into high value rock lobster (despite the quota leases costs such switches involve).

On face value, for the whole SESSF, fishing patterns and species targeting for risk averse fishers and risk seeking fisher seems to be as predicted. Risk seeking fishers are able to switching species and their capacity to rapidly change effort allows them benefit from opportunities as they arise. Even though cumulative realised catches are lower for risk seeking fishers, their realised CPUE is significantly higher as they are able to more easily reduce effort in a marginally profitable fishery.

For the five main fleets we find that the payoff for risk seeking has to take account of the increasing or decreasing biomass of target species and the relative profitability and diversity of the fleet. The ability to quickly reduce or increase effort is of crucial importance and will determine whether risk seeking behaviour will pay off in all situations. While payoff is important, as discussed in the introduction and background sections of this paper, empirical evidence suggests that minimising (catch) income variability is mostly the object of fisher behaviour with respect to risk. The variability in catch is greater for risk seeking fishers to that of risk averse fishers for the SESSF fishery as a whole and all trawl fleets. However, the catch variability for risk seeking fishers is lower for the flat head seine fishery which is a highly unprofitable fishery. A two tailed student $\mathrm{t}$-test indicates that the difference in the standard deviation for catch between the base case and the risk seeking fishers $(\mathrm{p}=0.074)$ and the risk averse and risk seeking fishers $(\mathrm{p}=0.100)$ is significant (at the $10 \%$ level). With respect to profit, there is greater variability in profit for risk seeking fishers in all fisheries except for the orange roughy trawl fishery which is characterised by a declining biomass. However the difference in the standard deviation for profit is not significant at the $10 \%$ level. 
In our study we investigate the appropriateness of using fisher responsiveness to information as a proxy for risk profile in an end-to-end fisheries model (Fulton et al 2007). We investigate if, in accordance with theoretical assumptions and empirical evidence, risk seeking (averse) behaviour pays off in terms of higher (lower) catches while incurring higher (lower) variability. Our analysis shows that the interpretation is not as straightforward as initially expected and the relationship between payoff and risk profile has to be considered in the context of three main fleet characteristics: whether the fleet is profitable; how diversified the fleet is; and whether the target species biomass is growing or in decline.

Our analysis shows that risk seeking behaviour pays off in terms of higher catches in fleets that are at least marginally profitable and are characterised by growing biomass or by biomass spikes (such as the deep trawl for flathead fleets and prawn trawl fleets in our case study). In unprofitable fleets, regardless of whether biomass is increasing (e.g. the Danish seine fleet for flathead) or in decline (e.g. the bottom trawl for orange roughy), risk seeking fisher's payoff comes in terms of avoided losses. By having greater 'flexibility' to reducing effort and thus decrease relative cost or increase CPUE, risk seekers are still 'better off' than their risk averse counterparts. In highly diverse fleets, characterised by multiple target species (in our case the bottom trawl for demersal species), there is little benefit to being risk seeking, possible because the risk is 'spread' regardless of risk type by the multiple species that can be fished.

The relationship between fishers risk profile and the effect on the variability in catch over time is also affected by the relative profitability of the fleet and biomass trends. In general it can be concluded that risk seeking fishers experience significantly greater catch variability, except in highly unprofitable fisheries, where their radical and immediate reduction in effort in fact reduces catch variability. However, even though risk seeking fishers also experience greater variability in profit, statistically their profit variability is not significantly different to that of risk averse fishers. In other words, if the object of the choice is to minimise income variability, as is suggested by empirical evidence, there is no benefit in being risk averse rather than risk seeking. However, in absolute terms, even though catches are not significantly higher for risk seeking fishers, these fishers are far more efficient (in terms of CPUE). The results of our simulations therefore confirm that fisher behaviour is as expected but that the resultant object of minimising variability is indeterminate.

At this point it is important to point out that there are a number of alternatives to our approach to modelling fisher risk perception. In our model traditional fisher are slower and less likely to radically change their behaviour in response to recent large fluctuations in catch than flexible fishers. In studies undertaken in other fields, such as agricultural economics, a different risk interpretation could be given to fisher's choice behaviour as modelled in Atlantis. Risk averse behaviour is often interpreted as moving away from strategies with high variance of income. However, in relation to tactical adjustments in extreme years where a tactical and dynamical response (i.e. being flexible) to unfolding opportunities and threats to generate additional income or avoid losses, is sometime interpreted as risk averse behaviour (e.g. Pannell et al 2000). This type of tactical and flexible behaviour has been observed in many empirical studies in the field of agricultural economics (e.g. Pannell et al 2000).

Not only can a different risk perception interpretation be given to our definition of seeking and risk aversion but several improvements to our incorporation of risk perceptions in Atlantis can be made. For instance, our assumption of risk profiles stability is challenged in the literature (e.g. Isaac and James 2000; Frechette 2005). It has been empirically shown that risk profiles are not stable over time. For instance, fishers may be more risk seeking in bad years. In most instances there is a preference for an immediate resolution of uncertainty that has negative consequences to delaying the resolution (e.g. Frechette 2005). A higher proportion of fishers become flexible in bad years. As fishers are not meeting their income targets they increase their risk taking behaviour (e.g. Smith and Wilen 2005). This is not dissimilar to biological models where there is a trade-off between being hungry and the need to leave cover to feed, thereby increasing risky behaviour (Walters et al 1997).

As shown above, our assumption of stability of risk profiles in bad years can be challenged. This also applies to our assumption that fisher's weight of catch and effort data over time is linear and diminishing over time. Anecdotal information suggests that fishers may, in fact, weigh catch and effort information from extreme years more heavily. For instance, fishers will more 'vividly' recall their location choices for years with catches that were significantly above average. If current catches resemble those of an extremely good year, 
van Putten et. al. The impact of fisher's risk perception on fishery outcomes....

fishers are more likely to repeat the location choice patterns of the 'past good year'. Fishers will also weigh location choice decision made in bad years differently. After all they will seek to avoid repeating decisions that, in their minds, led to outcomes that were significantly below average. As mentioned above, in these extremely bad years, they are less likely to repeat what they may view as mistakes and in fact implement a more flexible approach.

\section{REFERENCES}

Ajzen, I., 1985. From intentions to action: A theory of planned behaviour. In: Kuhl, J., Beckman, J.s (Eds.), Action-control: From Cognition to Behaviour. Springer, New York, pp. 11-39.

Ajzen, I., 1991. The theory of planned behaviour. Organizational Behaviour and Human Decision Processes $50,179-211$.

Allen, P.M., McGlade, J.M., 1986. Dynamics of discovery and exploitation: the case of the Scotian Shelf groundfish fisheries. Canadian Journal of Fisheries and Aquatic Sciences 43, 1187-1200.

Christensen, A., Raakjær, J., 2006. Fishermen's tactical and strategic decisions A case study of Danish demersal fisheries. Fisheries Research 81, 258-267.

Dwyer, P.D., Minnegal, M., 2006. The good, the bad and the ugly: risk, uncertainty and decision-making by Victorian fishers. Journal of Political Ecology 13, 1-23.

Frechette, D.L. 2005. How does aversion to intertemporal variation affect hedging behaviour? Agricultural Economics 33 (supplement), 389-398.

Fulton, E.A. 2010. Approaches to end-to-end ecosystem models. Journal of Marine Systems. doi:10.1016/j.jmarsys.2009.12.012

Fulton, E.A., Fuller, M., Smith, A.D.M. and Punt, A., 2005. Ecological Indicators of the Ecosystem Effects of Fishing: Final Report. Australian Fisheries Management Authority Report, R99/1546

Fulton, E.A., Smith, A.D.M., Smith, D.C., 2007. Alternative Management Strategies for Southeast Australian Commonwealth Fisheries: Stage 2: Quantitative Management Strategy Evaluation. Australian Fisheries Management Authority Canberra, p. 380

Fulton, E.A., Smith, A.D.M., Smith, D.C., Putten van, E.I., 2010. Human behaviour: The key source of uncertainty in fisheries management. Fish and Fisheries DOI: 10.1111/j.1467-2979.2010.00371.x.

Hatcher, A., Jaffry, S., Thébaud, O., Bennett, E., 2000. Normative and social influences affecting compliance with fisheries regulations. Land Economics 76, 448-461.

Hilborn, R., 1985. Fleet dynamics and individual variation: why some people catch more fish than others. Canadian Journal of Fisheries and Aquatic Science 42, 2-13.

Hilborn, R., and Ledbetter, M., 1979. Analysis of the British Columbia salmon purse-seine fleet: dynamics of movement. Journal of the Fisheries Research Board of Canada 36, 384-391.

Holland, D.S., Sutinen, J.G., 1999. An Empirical Model of Fleet Dynamics in New England Trawl Fisheries. Canadian Journal of Fisheries and Aquatic Science 56, 253-264.

Nøstbakken, L., 2008. Fisheries law enforcement-A survey of the economic literature. Marine Policy 32, 293-300.

Pannell, D.J. Malcolm, B., and Kingwell, R.S. 2000. Are we risking too much? Perspectives on risk in farm modelling. Agricultural Economics 23, 69-78.

Pascoe, S., Mardle, S., 2005. Anticipating fisher response to management: can economics help? CEMARE University of Portsmouth.

Pradhan, N.C., Leung, P.S., 2004. Modelling trip choice behaviour of the longline fishers in Hawaii. Fisheries Research 68, 209-224.

Putten, van E. I., Kulmala, S., Thébaud, O., Dowling, N., Hamon, K. G. Hutton, T., Pascoe, S. (2011) Behavioral drivers of fleet dynamics: Where theory meets practice, Fish and Fisheries DOI: 10.1111/j.1467-2979.2011.00430.x.

Smith, M.D., Wilen, J.E., 2005. Heterogeneous and correlated risk preferences in commercial fishermen: The prefect storm dilemma, The Journal of Risk and Uncertainty 31:1; 53-71.

Schnier, K.E. Horrace, W.C. and Felthoven R.G., 2009. The value of statistical life: Pursuing the deadliest catch, available from http:/www.uis.no/getfile.php/sv/seminar\% $20 \mathrm{kurt} \% 20$ schnier.pdf viewed on 5 May 2011.

Strand, I.E., 2004. Spatial variation in risk preferences among Atlantic and Gulf of Mexico pelagic longline fishermen. Marine Resource Economics 19, 145-160.

Sutinen, J.G., Kuperan, K., 1999. A socio-economic theory of regulatory compliance. International Journal of Social Economics 26, 174-193.

Symes, D., Hoefnagel, E., 2010. Fisheries policy, research and the social sciences in Europe: Challenges for the $21^{\text {st }}$ century. Marine Policy 34, 268-275. 